\title{
Glass as a Structural Material: Post-tensioned Glass T-Beam
}

\author{
Emrullah Koca ${ }^{1}$, Ahmet Türer ${ }^{2}$ \\ ${ }^{1}$ Department of Civil Engineering, Middle East Technical University \\ Çankaya-Ankara/Turkey \\ kocaemrullah90@gmail.com; aturer@metu.edu.tr \\ ${ }^{2}$ Department of Civil Engineering, Middle East Technical University \\ Çankaya-Ankara/Turkey
}

\begin{abstract}
Glass, traditionally, is used in buildings as windows because its strength capacity in windows is not significant. However, there is more demand for usage of glass such as beams, columns and decks. Glass' brittle nature has hindered its use as a strength carrying member. Aesthetics, recyclability, and transparency are the main reasons of the interest for glass in structural field. Moreover, glass may show significantly more benefits for certain types of projects such as historic building preservation and aesthetic buildings and bridges, where envelopments with minimal visual interruption are needed. However, more research should be done to be able to meet the demands and benefit from the advantages of glass. This study aims to contribute to the literature of structural glass and enhance the use of glass as a structural material, so a T-shaped glass beam is studied to develop a proper and safe design. Since glass is a brittle material and has high compressive strength and lower tensile strength, a T-beam is posttensioned in order to increase its initial fracture capacity and obtain ductile post-fracture performance. Several material tests are conducted to confirm the theoretical mechanical properties of glass as a material under compression and bending (indirect tension). After obtaining mechanical properties of the glass to be used in research, Finite Element Models (FEMs) of the T-beams were generated and analytical hand calculations were done for the same types of glass beams. Tests of T-shaped annealed (float) glass beams with and without post-tensioning were conducted. The results of the experiments were compared with the analytical hand calculations and FEMs. In this study, a glass T-beam was post-tensioned and its initial fracture capacity was increased. This resulted in a more ductile post-fracture performance, which would avoid sudden collapse and provide a safer fracture performance.
\end{abstract}

Keywords: Post-tensioned Glass Beam, Glass as a Structural Material, Glass Beam, Glass T-Beam

\section{Introduction}

\subsection{Glass Material}

Glass is an inorganic, visco-elastic, and isotropic material which has a non-crystalline molecular structure. The typical composition of glass consists of silica-SiO2 (70-74\%), lime-CaO (5-12\%), soda-Na2O (12-16\%) and other chemical elements with influence to transmittance, thermal properties, tensile strength, fracture toughness, and color etc. Glass has a high compressive strength (400-800 MPa) and a weaker tensile strength (40-50 MPa). A glass beam may be combined/supported with a material that is strong in tension in order to prevent the immediate breakage and make it useable as a structural material. Glass is recently preferred by architects because of aesthetics and continues to offer structural solutions, either by itself or used in combination with other materials, a trend which is very likely to continue in the future. In 1958 Pilkington and Bickerstaff introduced the revolutionary float glass process to the world, which yielded uniform thickness and very flat surfaces. There are several types of glass such as fully tempered, heat strengthened, float, laminated, and insulated etc. Brittle nature might be improved using certain laminates and admixtures. Some mechanical and physical properties of glass are as follows: density $(\rho)=2500 \mathrm{~kg} / \mathrm{m} 3$, modulus of elasticity $(\mathrm{E})=70 \mathrm{GPa}$, shear modulus $(\mathrm{G})=30 \mathrm{GPa}$, and poisson's ratio $(v)=0.23$.

\subsection{Literature Review}

The concept of post-tensioned glass beams has been studied in a limited number of researches. A T-sectioned glass beam composed of 3 layers of segmented annealed glass (laminated) was post-tensioned with a $7 \mathrm{~mm}$ diameter high strength steel tendon. [1] The effect of post tensioning on the buckling behaviour of a T-shaped glass beam was studied and the conclusion was that the geometry of the prototype had a relatively good resistance to buckling and the beam failed due to fracture of the glass. [2] Structural glass beams were tensioned on top and bottom of the beam and it was resulted that with a tendon increased the initial fracture strength of the beams. [3] These studies were elaborated to include different geometric variations and better performance in current study. 


\subsection{Objective and Scope}

T-shaped annealed (also named as "float" or "regular glass") glass beams with and without post tensioning were tested and results were compared with hand calculations and Finite Element Models (FEMs). Main aim of posttensioning a glass beam is to increase its initial fracture capacity and obtain ductile post-fracture performance, which would avoid sudden collapse and provide a more desirable post-fracture performance. Galvanized steel wire ropes were used as post-tensioning member for the glass beams. Aluminium "L" shaped angles were utilized to connect the web and flange of the T-beams. Analyses and calculation results were compared with the test results which were verifying successful design. Design tables were also generated; however, are not listed but can be reached at http://src.metu.edu.tr/tr/glassbeamtables.

\section{Material Tests}

Compression and bending (indirect tension) tests were conducted in order to confirm the theoretical properties of glass under compression and bending. Three cubes of float glass in 60x60x60 mm dimensions were tested in compression, which were composed of $6 \mathrm{~mm}$ thick glass pieces piled on top of each other. Loading rate of about 0.2 $\mathrm{MPa} / \mathrm{sec}$ for $5 \mathrm{kN} / \mathrm{sec}$ was used. Two of the samples failed prematurely and one achieved a compressive strength of 267 $\mathrm{MPa}$, which is much smaller than the $400 \mathrm{MPa}$. Multi-layered structure of test specimens were deemed to be the reason for low compressive capacity and bending test results were considered to be greater than $400 \mathrm{MPa}$. Bending tests of float glass samples were repeated for weak and strong bending axes in order to determine the bending (indirect tension) strength of the glass. Specimens used for bending tests had dimensions of 1000x200x6 mm and the specimens were loaded from $\mathrm{L} / 3$ and $2 \mathrm{~L} / 3$ points for constant bending region and loaded until failure. The displacement transducers (LVDT with $100 \mathrm{~mm}$ stroke and $0.006 \mathrm{~mm}$ resolution) and load cell $(3 \mathrm{mV} / \mathrm{V}$ output at full scale of $50 \mathrm{kN}$ with $5 \mathrm{~N}$ resolution) were used for measuring the mid-span deflections and applied total load. Lateral torsional bucking of slender direction were prevented using lateral sliding supports. Campbell Scientific CR1000 model data logger was used to digitize and record test date. Load-displacement graphs of float glass specimens were obtained (Figure 1) and bending based indirect tension capacities are obtained as 38.4, 44.9, and $40.64 \mathrm{MPa}$ for samples placed in their weak axes and 36.2 39.4, and 41.8 MPa for samples placed in their strong axes.
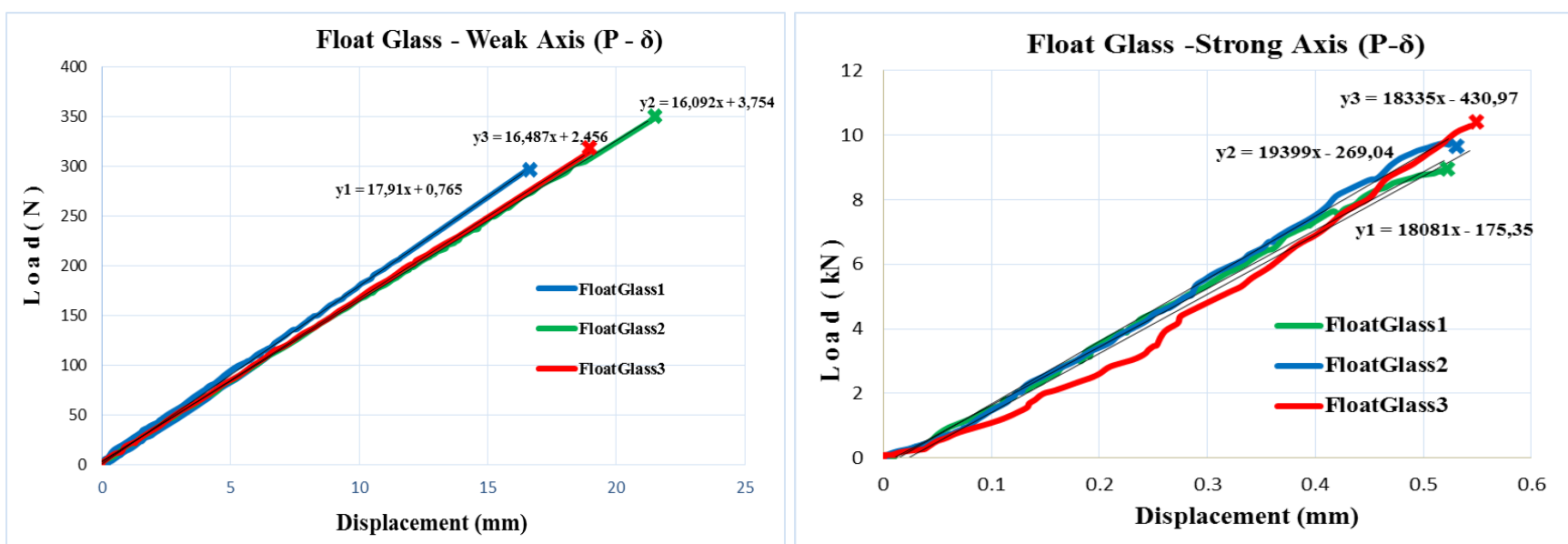

Figure 1: Load-displacement graph of float glass placed in their weak and strong axes

\section{Post-tensioned Glass T-Beam Calculations}

\subsection{Hand Calculations of T-Beam Capacity}

Simply supported T-Beam specimens with dimensions of 1000x100x6 mm were tested under 8-point loading. There are two main reasons of loading the beam at 8 points. Firstly, 8 point loading tests do not exist in the literature, while distributed load is very common for post tensioned beams. Secondly, 8-point loading provides a typical reverse moment diagram similar to the effect of post-tensioning, which is a much more feasible application. Preliminary hand calculations were done for T-Beams with and without post-tensioning according to the characteristic strength (32.64 $\mathrm{MPa})$ and modulus of elasticity $(62.10 \mathrm{GPa})$ obtained from the material tests. Simple deflection, maximum shear force 
and moment calculations and post-tensioning effects are superimposed and iteratively determined to satisfy transfer case, bending (tension-compression), bearing failure, shear strength using Excel sheet and equations in Figure 2.

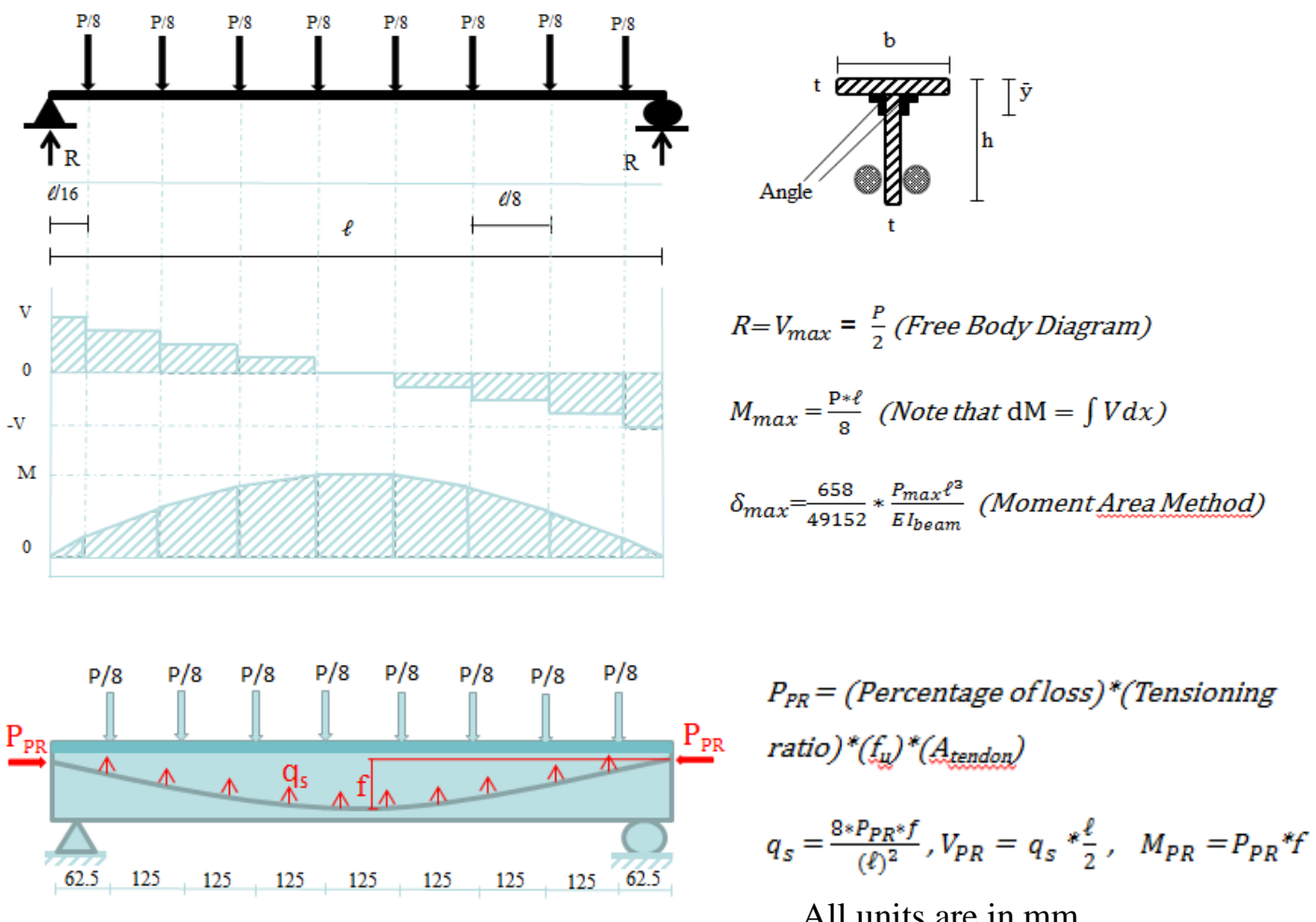

All units are in $\mathrm{mm}$

Figure 2: Demonstration of loads on T-beam and calculation equations

Stress check calculation results for glass beam with and without post-tensioning are done using Excel sheet after optimization for both in transfer (short term) and final (long term) cases and tabulated below (Table 1).

Table 1: Calculation results of T-beam with and without post tensioning

\begin{tabular}{|c|c|c|c|c|c|}
\hline \multirow{4}{*}{$\begin{array}{c}\text { Transfer } \\
\text { Case }\end{array}$} & \multicolumn{2}{|c|}{ Post-tensioned T-beam } & \multicolumn{2}{c|}{ T-beam without Post-tensioning } \\
\cline { 2 - 6 } & $\mathrm{P}_{\mathrm{PR}}(\mathrm{kN})$ & 8.26 & 8.26 & \multicolumn{2}{c|}{ Ultimate Results } \\
\cline { 2 - 6 } & $\delta_{\text {transfer }}(\mathrm{mm})$ & 0.62 & 0.62 & $\mathrm{P}_{\max }(\mathrm{kN})$ & 4.86 \\
\cline { 2 - 6 } & $\sigma_{\text {top }}(\mathrm{MPa})$ & 5.00 & 5.00 & $\sigma_{\text {max }}(\mathrm{mm})$ & 0.66 \\
\cline { 2 - 6 } & $\sigma_{\text {bottom }}(\mathrm{MPa})$ & -37.89 & -37.89 & $\sigma_{\text {bottom }}(\mathrm{MPa})$ & -11.94 \\
\hline \multirow{5}{*}{ Final Case } & & & & & 32.64 \\
\hline & $\mathrm{P}_{\text {des/crack/ult. }}(\mathrm{kN})$ & 7.157 & 10.53 & $\tau_{\text {neutral axis }}(\mathrm{MPa})$ & 5.34 \\
\cline { 2 - 6 } & $\delta_{\text {final }}(\mathrm{mm})$ & 0.35 & 0.81 & $\tau_{\text {glue point }}(\mathrm{MPa})$ & 4.50 \\
\cline { 2 - 6 } & $\sigma_{\text {top }}(\mathrm{MPa})$ & -12.59 & -20.68 & - & - \\
\cline { 2 - 6 } & $\sigma_{\text {bottom }}(\mathrm{MPa})$ & 10.20 & 32.30 & - & - \\
\cline { 2 - 6 } & $\tau_{\text {neutral axis }}(\mathrm{MPa})$ & 5.13 & 6.34 & - & - \\
\cline { 2 - 6 } & $\tau_{\text {glue point }}(\mathrm{MPa})$ & 4.33 & 5.34 & & - \\
\hline
\end{tabular}

As it can be seen from the table, the load carrying capacity of the beam is increased by about 2.2 times (Incresed from $4.86 \mathrm{kN}$ to $10.53 \mathrm{kN}$ ) with respect to the original case without post-tensioning. 


\subsection{Analytical Modelling of the T-Beams}

Software Analysis SAP2000 (v.20) was used in order to model the Finite Element Models (FEMs) of the posttensioned glass T-beams. The materials were defined as follows: Glass as thin shell with $12.5 \times 12.5 \mathrm{~mm}$ mesh size, aluminium L shaped angles as frame sections, and post-tensioned wire rope as tendon. Post-tensioning load after losses was calculated as $8.26 \mathrm{kN}$ for float glass and applied on double tendon members on both side of the web glass. After tendon preloading, the beam was also loaded to the ultimate load to obtain the stresses at top and bottom of the midspan. The model results were obtained for transfer (Figure 3) and final loading cases (Figure 4). FEM results of Tbeams with and without post-tensioning at their mid-spans are tabulated in Table 22.

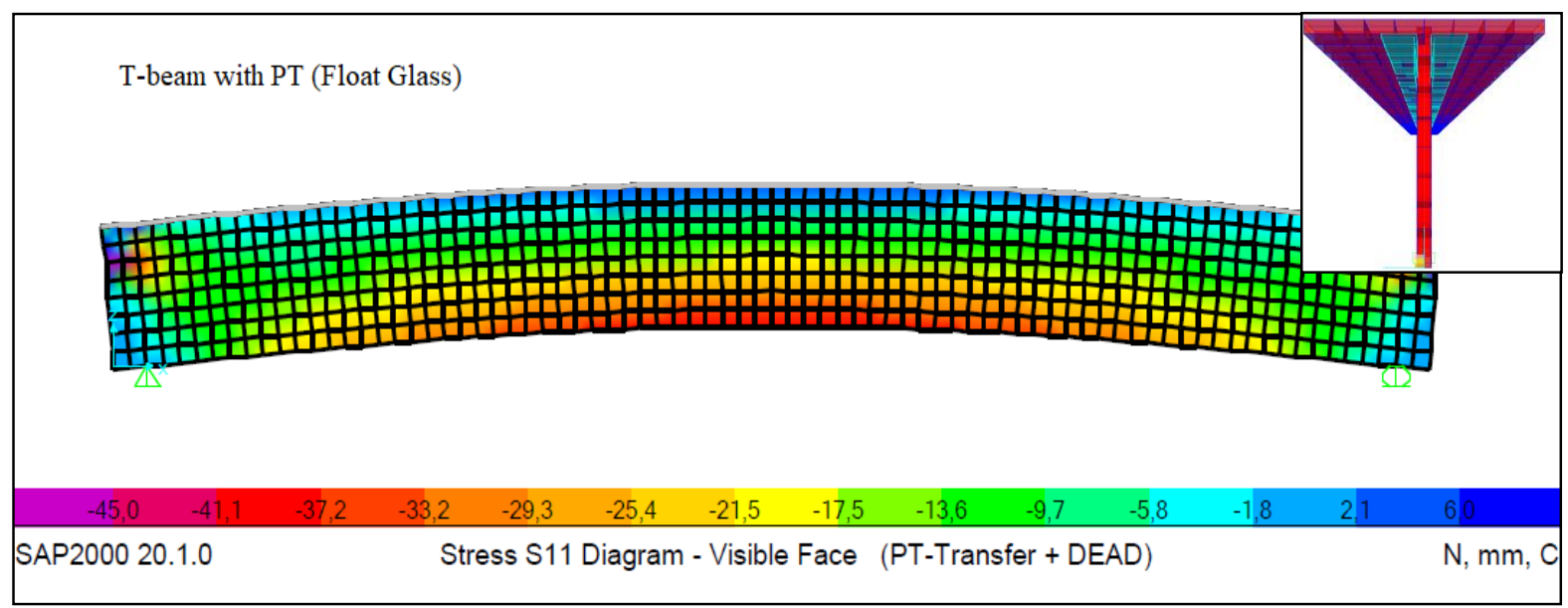

Figure 3: Stresses at transfer case of post-tensioned float glass T-beam

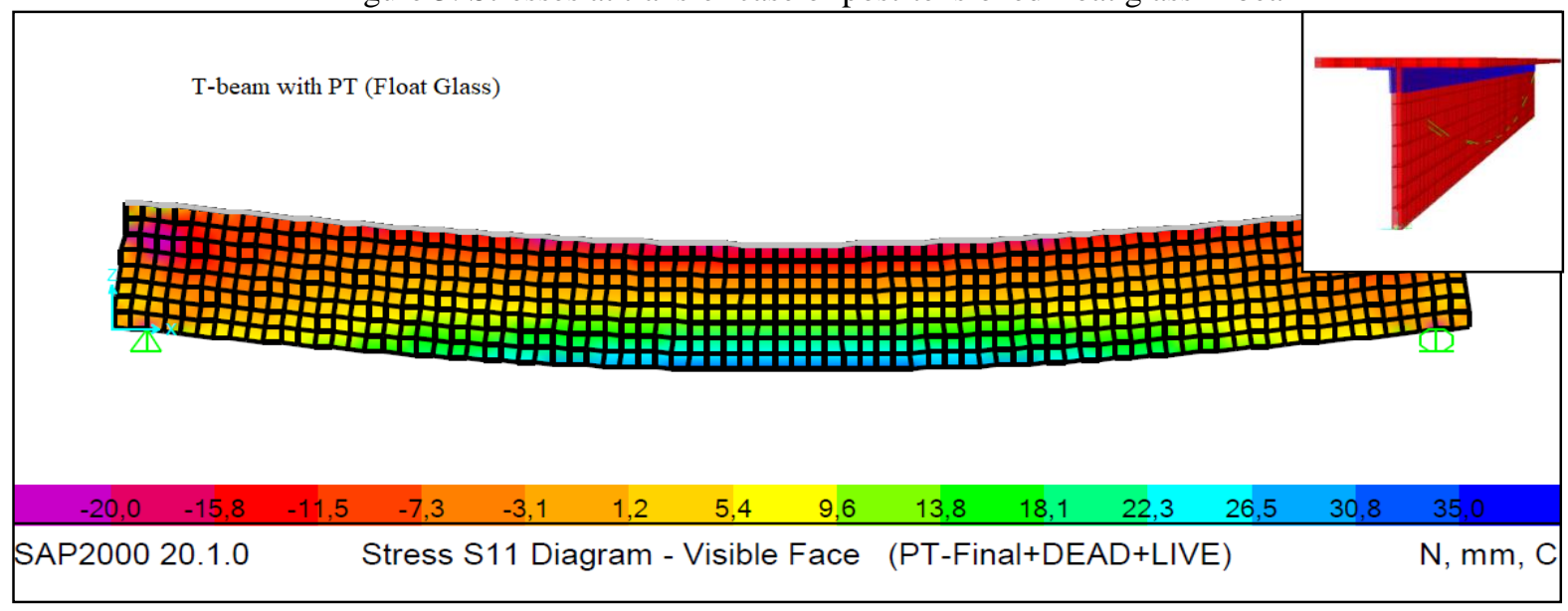

Figure 4: Stresses at final case of post-tensioned float glass T-beam

The finite element model results were also very close to hand calculations both for float glass with and without post-tensioning as seen in Table 2 .

Table 2: FEM results of T-beam without post tensioning

\begin{tabular}{|c|c|l|c|}
\hline & T-beams without PT & \multicolumn{2}{c|}{ T-beams with PT } \\
\hline & & \multicolumn{1}{|c|}{ Transfer Case } & Final Case \\
\hline$\delta_{\max }(\mathrm{mm})$ & 0.70 & 0.70 & 0.82 \\
\hline$\sigma_{\max , \text { tensile }}(\mathrm{MPa})$ & 33.12 & 4.88 & 32.73 \\
\hline$\sigma_{\max , \text { compressive }}(\mathrm{MPa})$ & -13.23 & -39.22 & -23.82 \\
\hline
\end{tabular}




\section{Post-tensioned Glass T-Beam Tests}

T-Beam specimens were prepared for the tests with and without post-tensioning. The web and flange of the TBeam were $1000 \mathrm{~mm}$ in length, $100 \mathrm{~mm}$ in height, and $6 \mathrm{~mm}$ in thickness. The composite action between the flange and web parts of the glass T-beam was utilized using two aluminium L15x15x1.2mm profiles by the help of polyurethane based adhesive (Akfix 610-conforms to D4 according to DIN EN 204). The aluminium type used is AA6063-T6 which has about $152 \mathrm{MPa}$ shear strength and its modulus of elasticity is the same as the glass (70 GPa). The test beams were restrained from either side for additional stability which will not be necessary in real case applications because of the flange and deck. Post-tensioning tendon was selected as $8 \mathrm{~mm}$ diameter galvanized steel wire rope. The set-up of T-beam tests with and without post-tensioning is displayed in Figure 5.
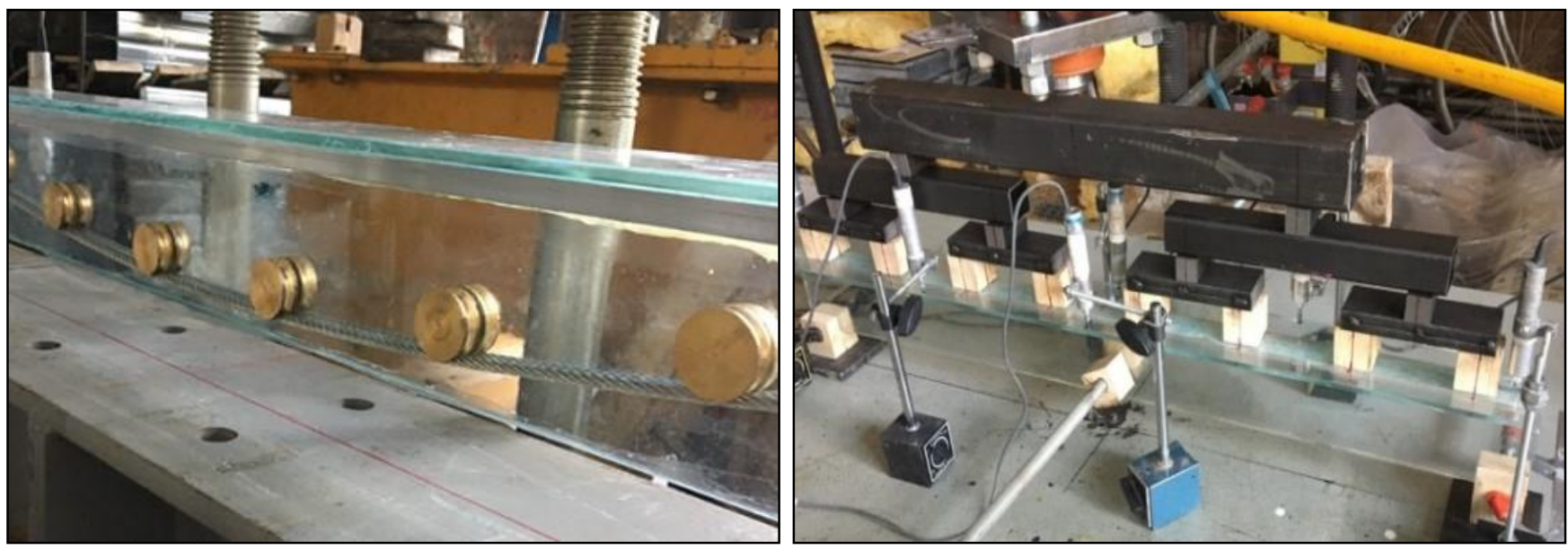

Figure 5: Test set-up of T-beam with and without post tensioning

The load-displacement graphs of float glass T-beam specimens are given in Figure 6. The results for averages of maximum load (Pmax), maximum deflection ( $\delta \max )$, graph secant slope values obtained from the tested samples without post-tensioning are obtained as $4.76 \mathrm{kN}, 0.63 \mathrm{~mm}$, and $7.6 \mathrm{kN} / \mathrm{mm}$, and for post tensioned glass samples as $11.14 \mathrm{kN}, 0.75 \mathrm{~mm}, 0.61 \mathrm{kN} / \mathrm{mm}$, respectively. The glue material satisfied full composite action and T-beam concept was accepted after comparing the results.
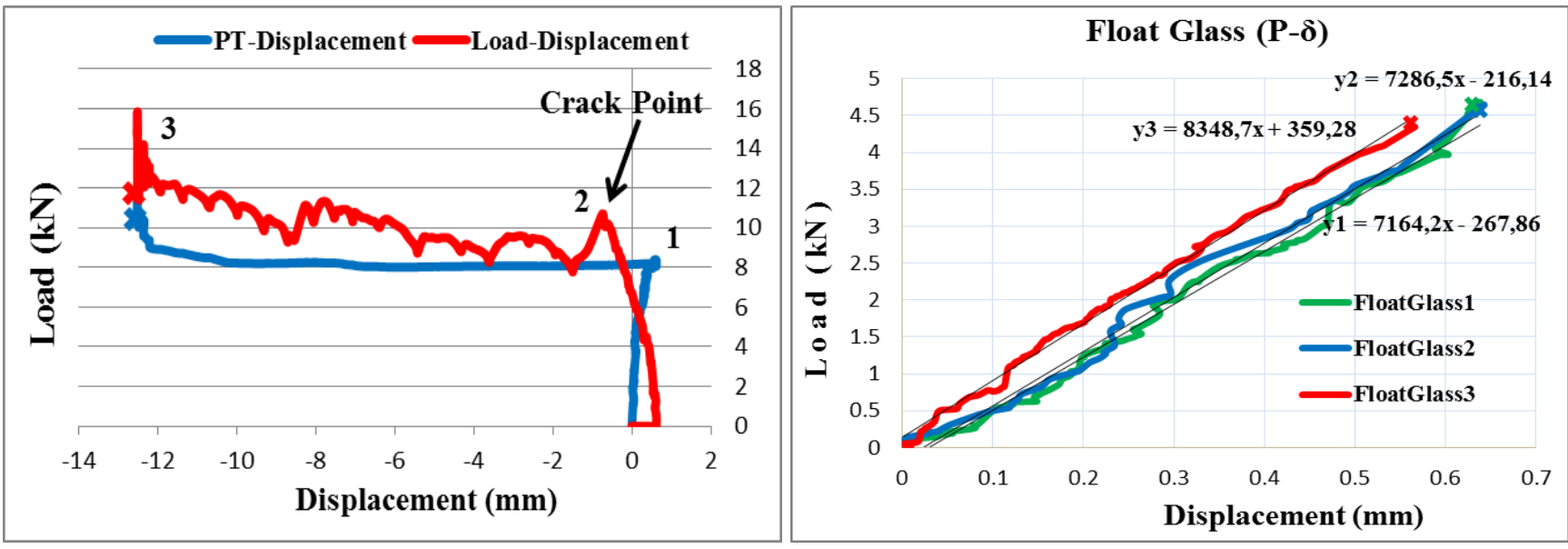

Figure 6: Test set-up of T-beam with and without post tensioning

The post-tensioned float glass T-beam was tensioned to $8.26 \mathrm{kN}$. The beam deflected upward at its mid-span to the value of $0.62 \mathrm{~mm}$ corresponding to $8.26 \mathrm{kN}$ post-tensioning (Point 1 in Figure 6). Then, the beam was loaded at 8 points and it cracked at $10.86 \mathrm{kN}$ corresponding to $0.749 \mathrm{~mm}$ downward deflection at its mid-span (Point 2 in Figure 6). The first cracks occurred at constant zone which includes the mid-span of the beam. While the sample was kept on loading 
more cracks occurred along the length of it (Between points 2 and 3 in Figure 6.). The beam was unloaded at $15.72 \mathrm{kN}$ which corresponds to a $12.5 \mathrm{~mm}$ deflection at its mid-span. The float glass without post-tensioning fractured at the constant moment zone due to tensile stress after loading the sample. The crack started at the constant moment zone of tensile area and fragmented upwards to the compression zone in the sample without post tensioning. Fractured samples of both T-beam with and without post tensioning are demonstrated in Figure 7.
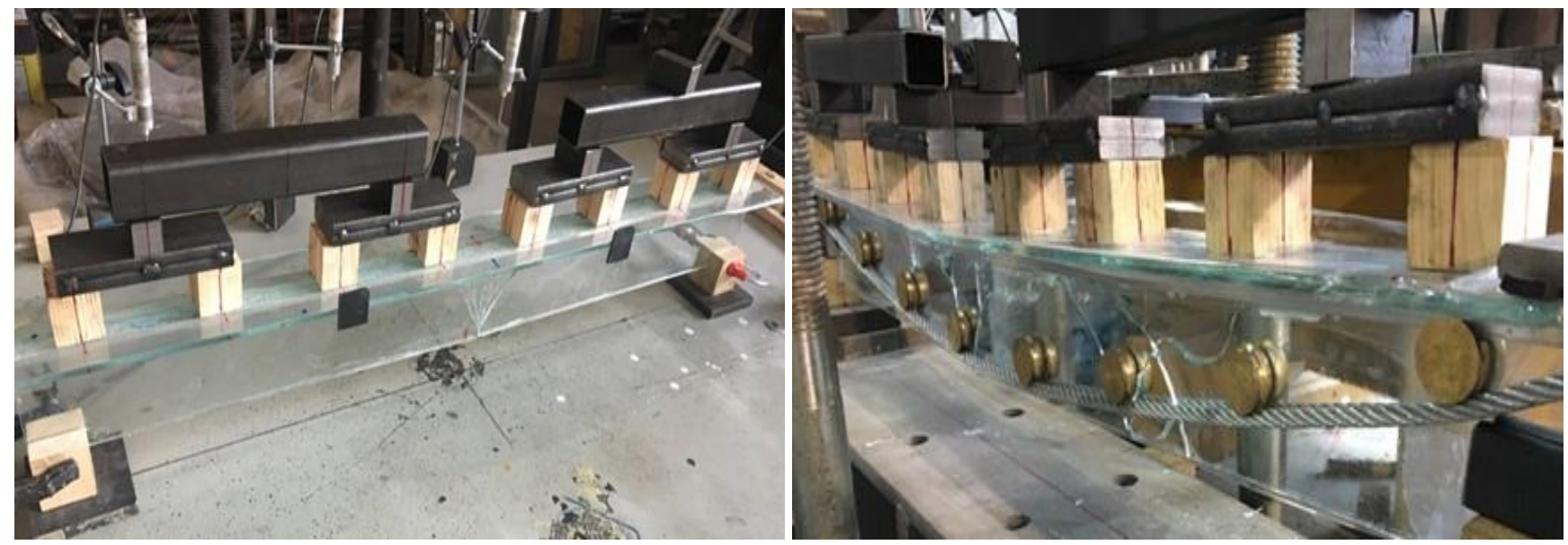

Figure 7: Float glass T-beam tests with and without post-tensioning after fracture.

\section{Conclusion}

This study, firstly, made a contribution to the structural glass literature. It has also showed that curved posttensioning for float glass T-beam is possible for application in the construction field. A significant ductility has been improved after post tensioning a glass T-beam. The initial crack load increased from $4.76 \mathrm{kN}$ to $11.14 \mathrm{kN}$ after post tensioning (about 2.5 times). The cracking and ultimate deflections as well as the linear extrapolation of cracking force and ultimate force had a ratio in the order of 15 . This shows a much superior post-cracking performance compared to ordinary structures. The strength and ductility increase proves that glass T-beams can be safely used in architectural designs. Furthermore, cracking of glass may be a good indication to repair and reserved displacement capacity is a plus of such a T-beam. Another result of this study was that the test results showed good correlation in the range of about $\pm 4 \%$ with both hand calculations and FEMs. These results can be deemed as in well agreement, considering that the glass test results had a scatter of about $\pm 5 \%$. It can be concluded that both hand calculations and FEMs are valid for the design of post-tensioned glass T-beams. This application may have revealed that post-tensioned float glass shows similar behaviour as reinforced concrete beams. However, UV and IR filters might be used to prevent greenhouse effect.

\section{References}

[1] Bos, FP., Veer, FA., Hobbelman, GJ., \& Louter, PC. (2004). International Conf. on exp. L mechanics/icem12/advances in exp. mechanics (p. 1-9). Bari: Politecnico di Bari.

[2] Belis, J., Louter, C., Verfaille, K., Van Impe, R., \& Callewaert, D. (2006), The effect of post-tensioning on the buckling behaviour of a glass T-beam. In International Symposium on the Application of Architectural Glass ISAAG, (p. 129-136).

[3] Louter C., Nielsen J.H., Belis J. (2013), Exploratory experimental investigations on posttensioned structural glass beams. International Conf. on Structures and Arch. (ICSA)

[4] Koca E. \& Türer A.(2019), Modeling, Design, and Tests of Post-Tens. Glass T-Beams.

[5] EN 572-1: (2004, July), Glass in building - Basic soda lime silicate glass products-Part 1-2: Definitions and general physical and mechanical properties. 